\title{
132.
}

\section{MIXED CONCEPTIONS OF JUSTICE}

AWLS CALLS A conception of justice a mixed conception when it combines his first principle, the principle of equal liberties, with a principle of distributive justice other than his second principle, such as average utility (T7 I07 and \$49).

Mixed conceptions help clarify the justification of principles from the original position. In the 1999 revised edition of $T 7$, Rawls expresses regrets not to have presented the argument from the original position for the two principles of justice by way of a comparison with a mixed conception:

It would have been better to present [the argument] in terms of two comparisons. In the first parties would decide between the two principles of justice, taken as a unit, and the principle of (average) utility as the sole principle of justice. In the second comparison, the parties would decide between the two principles of justice and those same principles but for one important change: the principle of (average) utility is substituted for the difference principle. (The two principles after this substitution I called a mixed conception, and here it is understood that the principle of utility is to be applied subject to the constraints of the prior principles: the principle of the equal liberties and the principle of fair equality of opportunity.) (T7 xiv, emphasis added)

In contrasting this mixed conception with justice as fairness, Rawls is able to separate out arguments for the equal basic liberties and their priority, and for fair equality of opportunity, from the argument for the difference principle. Rawls considers that the arguments for the equal basic liberties and their priority 
are very strong, and would be established by a first comparison between his two principles and an unconstrained principle of average utility as the sole principle of justice. (The principle of average utility says that the institutions of the basic structure are to be arranged so as to maximize the average welfare of the members of society.) The parties assume that they have an interest in the fulfillment of their moral and religious conceptions. The two principles protect the basic rights and liberties and provide an adequate complement of the primary goods to exercise and enjoy those freedoms. To agree to the principle of average utility might jeopardize those rights and liberties, in particular for minorities. Therefore the parties would not take this kind of risk. Furthermore, the basic liberties protect fundamental interests that have a special significance: thus the priority of the first principle over the second.

By contrast, Rawls considers that a second comparison, focused on advantages of the difference principle, involves more delicate considerations. In this second comparison Rawls's two principles of justice are contrasted with the same principles with one change: the principle of average utility combined with a social minimum is substituted for the difference principle. This mixed conception is the principle of restricted utility. The basic structure maximizes average utility, but under two constraints: first equal basic liberties and fair equality of opportunities are guaranteed, and second a suitable social minimum is also introduced. The social minimum is intended to meet essential human needs; its incorporation in the mixed conception makes the principle of restricted utility a particularly robust alternative to the two principles of justice. Rawls concedes that his two principles and a principle of restricted utility might not be very far apart if we restrict ourselves to the social policies which would result from the principles. In particular, the least well off are assured not only against denial of liberties or opportunities, but also against serious losses of well-being. Still, this might not be sufficient for the worst off to feel "that they are a part of political society" ( $\left.\mathcal{F} F_{\text {I }} 27\right)$. Therefore, the crucial consideration which weighs in favour of the difference principle over the principle of restricted utility is the Ralwsian idea of society as a fair system of cooperation. In a society arranged as a fair system of cooperation between citizens, a principle of reciprocity whereby those who are better off are not better off to the detriment of those who are worse off is superior to a maximizing principle such as average utility however constrained. This suggests that behind the veil of ignorance the parties would endorse the difference principle. That is: they would choose a principle whereby those who gain more do so on terms acceptable to those who gain the least.

Why is it so important for Rawls to make the comparison between his principles and the mixed conception of restricted utility? First, because it allows us 
to understand more deeply the contrast between the utilitarian's conception of society as a system arranged to produce most good over all of its members and the Rawlsian idea of society as a fair system of cooperation. Second, because this comparison between a mixed conception and Rawls's two principles highlights that the argument for the difference principle does not rest, pace what Arrow, Harsanyi, and many others had thought, on aversion to risk, but rather on reciprocity between citizens regarded as free and equal.

Veronique Munoz-Darde

SEE ALSO:

Arrow, Kenneth

Difference principle

Harsanyi, fohn

The original position

Perfectionism

Publicity

Social minimum

Two principles of justice (in justice as fairness)

Utilitarianism

Utility 